\title{
Stress Fractures of the Tibia after Jogging
}

\section{Castro SD*, Joosse P, Unlu C, and Steller EP}

Department of surgery, Sint Lucas Andreas Ziekenhuis, Jan Tooropstraat 164, 1061 AE, Amsterdam, Netherlands

${ }^{*}$ Corresponding author: Steve de Castro, Medical Center Alkmaar, Department of surgery, PO Box: 501, 1800 AM Alkmaar, Netherlands, Tel: +3172 548 4444 , Email: stevedecastro@gmail.com

Rec date: Dec 10, 2013, Acc date: Apr 25, 2014, Pub date: Apr 27, 2014

Copyright: ( 2014 Castro SD, et al. This is an open-access article distributed under the terms of the Creative Commons Attribution License, which permits unrestricted use, distribution, and reproduction in any medium, provided the original author and source are credited.

\begin{abstract}
Stress fractures of the tibia seldom occur and the diagnosis is easily overlooked. Radiological signs may be subtle and the majority of cases will heal after a sufficient period of immobilization. The following description of two cases and subsequent review of the literature provide helpful information for the clinician to recognize, diagnose and treat stress fractures of the tibia.
\end{abstract}

Keywords: Fractures; Stress; Tibia; Radiography

\section{Introduction}

A stress fracture is bone fracture which can be partial or complete and results from repeated application of stress the bone. This stress is lower than the stress required to completely fracture the bone in one instance. Healthy athletes, especially runners and military personnel generally sustain these injuries. Stress fractures account for up to $20 \%$ of sports related injuries. The site most commonly affected is the 2 nd metatarsal bone. Stress fractures of the tibia seldom occur and the diagnosis is often overlooked as we would like to illustrate with the following two cases of patients with stress fractures of the tibia. A description of the cases is followed by a review of the literature on pathofysiology, presentation, diagnostic work-up and management of stress fractures of the tibia.

\section{Case 1}

A forty-nine year old male patient presented himself to the emergency room with the complaint of pain in the right leg after jogging. The pain occurred a week ago and started after jogging. Beforehand there were no complaints at all (e.g. shin splints). The pain was described as an ongoing sensation during jogging which got so severe after a while that he discontinued jogging. The pain was located at the anterior $2 / 3$ distal part of the shin of the right tibia. The patient had full function of his leg and was able to go to work the whole week. Upon examination we saw painful, red, tender mass located at the anterior $2 / 3$ distal part of the right tibia. His body temperature was $37.6^{\circ} \mathrm{C}\left(99.7^{\circ} \mathrm{F}\right)$ and he had no calf tenderness. Pulsations of the dorsal and posterior tibial artery were intact. There were no wounds visible upon examination. In his history, the patient sustained a distal fibula fracture in the past which was managed conservatively. We examined the old $\mathrm{x}$-rays and saw no difference in the healed fibula fracture. We treated the patient with antibiotics under the working diagnose of having superficial skin infection.

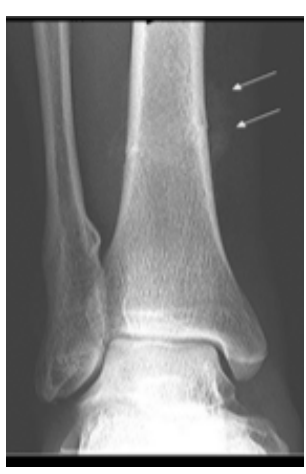

Figure 1: Anterior-posterior $\mathrm{x}$-ray showing irregularity at the bone cortex without any disruption of the distal tibia and early callus formation. The white arrow shows callus formation

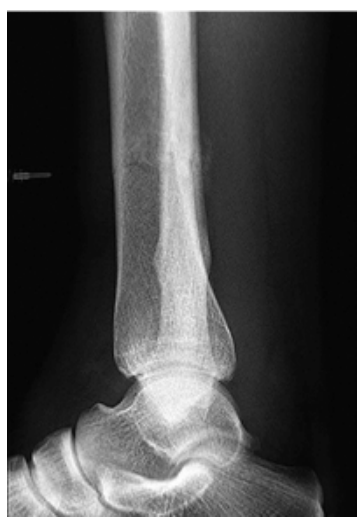

Figure 2: Lateral $\mathrm{x}$-ray showing a horizontal fissure of the distal 2/3 of the tibia without any periostal reaction

After 5 days the redness had not subsided and we made an X-ray of his lower leg. On the X-ray we say a fissure of the tibia without any periostal involvement correlating with the site of the redness (Figure 1 
Page 2 of 4

and 2). We also saw early callus formation (see arrows in Figure 1).The distal fibula showed signs of union of the aforementioned fibula fracture. A subsequent MRI (Figure 3) was performed and showed oedema of the bone marrow around the fracture line and callus formation and no signs of a pathological fracture. The old fibula fracture showed no signs of a refracture. The bone cortex was undisrupted. The patient was diagnosed as having a stress fracture of the tibia and received a circular polymer resin cast for 6 weeks with excellent results. A Bone mineral density (BMD) of the proximal femur and lumbar spine as measured by DXA showed normal values.

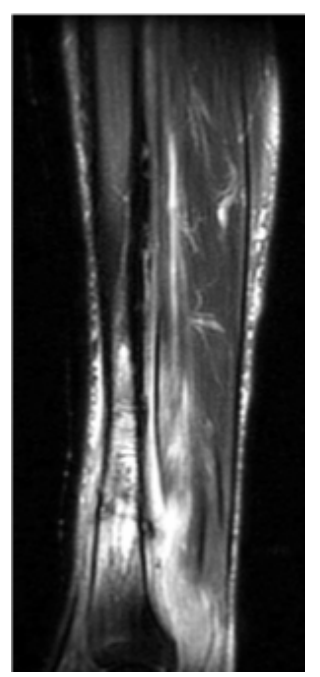

Figure 3: The lateral MRI also shows the fracture line with periostal callus formation.

\section{Case 2}

A fifty-nine year old female who works at our hospital mentioned that she had been having pain in her left knee during our routine rotations. She told us that she had been suffering from osteoarthrosis of the left knee and underwent a medial meniscectomy 8 years ago. Beforehand there were no complaints of shin splints. She also mentioned that she started an exercise regime 8 weeks ago, which included jogging. The pain started immediately after one jogging session. The patient thought that is was related to her athrosis of her knee and temporarily stopped her exercise regime. She had been having this pain for last 6 weeks and did not go to a physician. During physical examination of the knee we found no abnormalities. Provocation tests (i.e. drawers test, Lachman and Mcmurrays test) where negative. An X-ray of her left knee (Figure 4) showed osteoarthrosis of medial knee compartment and a translucent patchy spot in proximal tibia. The MRI (not shown) revealed showed oedema of the bone marrow around the fracture line and callus formation and no signs of a pathological fracture. This patient was managed conservatively with an above the knee circular polymer resin cast for 6 weeks. During clinical examination after 6 weeks the patient still complained of axial compression pain and the X-ray showed union and callus formation. The patient received a new cast for an additional 6 weeks. After six weeks the patient was symptom free. A Bone mineral density (BMD) of the proximal femur and lumbar spine as measured by DXA showed normal values.

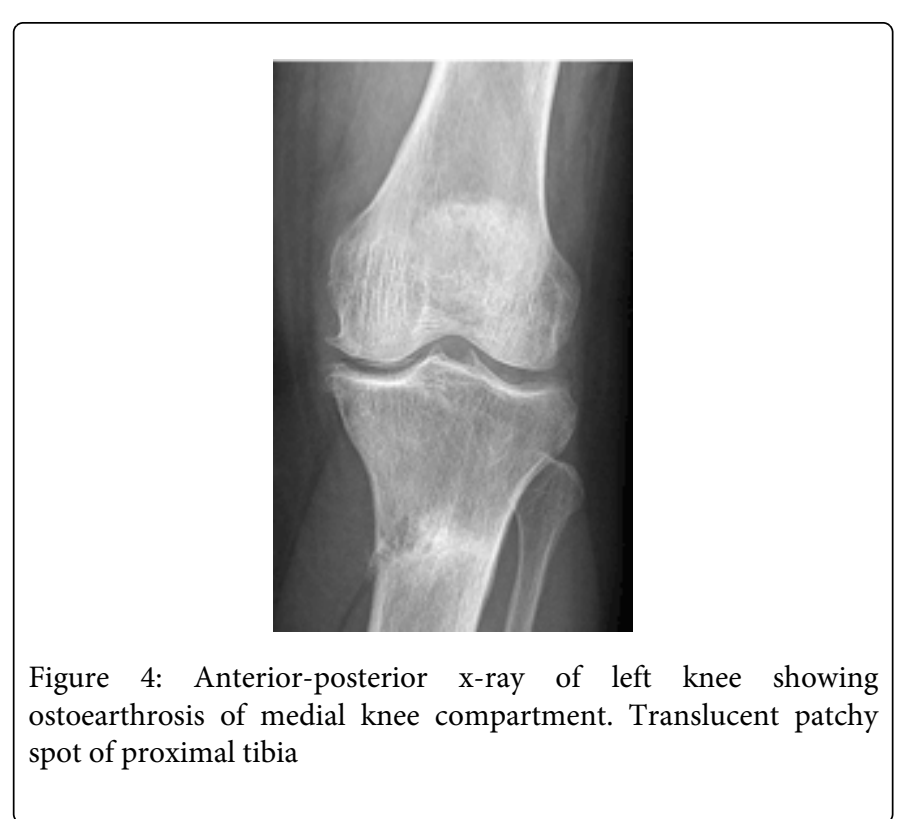

\section{Discussion}

Stress fractures where first described in the mid-19th century in a young German soldier who complained of swelling and pain in his foot after marching [1]. In 1897 with the advent of the Rontgen ray it was shown that these symptoms were caused by a fracture of the second metatarsal bone [2]. The present two cases illustrate that a stress fracture of the tibia does not immediately come to mind when a patient presents with discrete pain in the leg to an emergency room.

\section{Pathophysiology and risk factors}

Biomechanically, the occurrence of stress fractures of the tibia, appear to be most related to loading rates. Loading rate is one of the factors associated with its fatigue limit. The fatigue limit of a tissue is related to the type of load applied, its peak magnitude, loading rate, and the total dose. The type of load consists of a combination of compression and bending [2,3]. Most studies of stress injuries describe some change in the training regimen as the causative factor for the injury.3 For instance, it has been documented that there is an increased tibial stress fracture rate in runners with an increasing distance beyond approximately $32 \mathrm{~km} / \mathrm{wk}$ [4]. Also important is any change in the training program, including a sudden increase in mileage, pace, volume, or cross-training activity without adequate time for physiologic adaptation. Hard training surfaces also is an important risk factor [5].

Giladi et al. [6], analyzed 300 military recruits, and found 2 independent variables in the anatomy considered major risk factors for stress fracture. These include a narrow width of the tibia and increased exorotation at the hip joint. A study performed by Bennell et al. [7] reported that female running athletes with stress fractures had a smaller calf circumference and less lean muscle mass in the lower limb. This correlates with Garrett [8]. who have shown that one of the major role of the calf muscles is energy absorption. A cross-sectional study comparing 23 running athletes with a history of tibial stress fracture and 23 who have never sustained a stress fracture found that the stress fracture group had a significantly smaller tibial cross-sectional on computed tomography than the non-stress fracture group [9]. In 
contrast a study by Cleek [5]. Reported that the repetitive loading history of runners in a single plane leads to an asymmetric crosssectional geometry of the tibia. In contrast, soccer players who load in multiple directions were found to have much more symmetric bone geometry.

Most studies report that stress fractures occur more often in females compared to males [10]. This has also been reported in the military where female cadets undergoing similar training programs have an increased risk of stress fractures, ranging from 1.2 to 10 times $[3,11]$ In athletes, the results are less obvious. Female athletes generally develop menstrual irregularity and disordered eating pattern resulting in osteoporosis which increases the risk of developing stress fractures. This contributes to findings that most studies report that females are at an increased risk for stress fractures [12,13] Some studies have reported an increase in risk for female athletes ranging from 1.5 to 3.5 times [14,15] In contrast, another large study has failed to show difference in the risk of stress fractures between female and male athletes sex [16].

\section{Presentation}

The typical history of a stress fracture is that of localized pain. The pain is not present at the start but occurs toward the end of the physical activity. This pattern is generally opposite to that of many soft tissue injuries that have pain the morning after the training. Generally, the pain occurs earlier during the physical activity and lasts longer and will be present throughout the training. The pain subsequently persists into daily ambulation. A careful history is critical and often reveals a change in the training program. The physical examination typically reveals local tenderness over the involved bone. Other examinations for the clinical detection of stress fracture such as the hop test are helpful. However these are not as reliable as direct palpation. Risk factors that can be detected on physical examination should be looked for. These risk factors include various alignment of the lower extremity, leg length discrepancies, femoral neck exorotation, muscle weakness and calf circumference [17].

\section{Diagnostic work-up}

Radiographic signs are usually seen after 2 to 8 weeks of symptoms, and in the early stages of these injuries. Unfortunately, the sensitivity of these radiographic signs may be as low as $10 \%$. Radiography findings can correlate with the MRI signs of the fracture line or callus, but the early phases of bone stress injuries verified with MRI cannot reliably be seen with radiographs [18]. The most common sign in early stress fractures is a region of focal periosteal bone formation. A cortical area of decreased density may also be seen and usually is an early sign of a stress fracture [19]. Focal hyperemia and edema with early resorption of calcium deposits are possibly responsible for this initial graying of the cortex. Other radiological abnormalities may include signs of osteopenia, endosteal reaction, an ill-defined bony cortex, and, in severe cases a complete fracture. Radionuclide scanning is a more sensitive but less specific method for imaging bony stress injuries and can provide the diagnosis as early as 2 to 8 days after the onset of symptoms [20].

Computed tomography scan is useful in differentiating conditions that mimic stress fractures on bone scan, such as osteoid osteoma, osteomyelitis, and various malignancies. It is also helpful in detecting fracture lines as evidence of stress fractures and often can differentiate between stress fracture and stress reaction [21].
Magnetic resonance imaging with fat suppression makes it possible to grade the progressive stages of stress fracture severity [18,22-33]. Magnetic resonance imaging is associated with a high sensitivity for pathology. A magnetic resonance imaging examination can precisely define the location and extent of bony injury with the added benefit of lack of ionizing radiation exposure. Overuse of this diagnostic modality is illustrated by a study by

Bergman [25]. In which 21 runners without symptoms were followedup with MRI and nine (43\%) of them showed abnormalities indicating stress injuries. After 12 months, none of the asymptomatic runners developed a frank bone stress injury. These results show the importance of correlating MRI findings with the clinical findings.

\section{Management}

Management depends on the extent of the fracture. Minimal stress reaction without a fracture line can be managed with the temporary cessation of running activities to allow for bony repair. This can range from a few days for a minor stress fracture to 12 weeks for a severe stress fracture. If the pain persists with daily activities, a tibial brace can be used to immobilize distal and mid-tibial injuries [26-34]. The medial tibial plateau as seen in the present case report is an unusual site of stress fracture [27,28]. Use of a long-leg non weight-bearing immobilization may be necessary, especially with a cortical discontinuity. Stress fractures of the anterior cortex of the mid-tibia as seen in this case report are also unique and require a different treatment regimen. These occur on the tension side of bone in a region of reduced perfusion and are prone to delayed union or even worse to progression to complete fracture. These patients also require treatment with no weight-bearing immobilization for 6 to 8 weeks. Finally, surgical placement of an intramedullary fixation is indicated after 3 to 6 months of fails conservative management [29,30]. The Short Musculoskeletal Function Assessment Questionnaire (SMFA) can be used to objectively measure outcome [31].

\section{Conclusions}

The tibia is an uncommon site for stress fractures. However, the diagnosis should be considered in patients who present with localized pain over the tibia that is related to the duration and intensity of physical activity. Long distance running, an alteration in training program and hard training surfaces may contribute to a high index of suspicion. Early radiological signs, i.e. focal periosteal bone formation and 'gray' cortex sign may be subtle in nature. In patients with a typical history and/or presentation and no signs on conventional Xray the diagnostic work-up should include a CT-scan and/or a MRI. In most cases (non) weight bearing immobilization will lead to uneventful recovery. Delay in diagnosis and treatment should be avoided, since this can result in progression to a complete fracture or a non-union, especially on the anterior cortex of the mid-tibia.

\section{References}

1. Breithaupt J (1855) Zur Pathologie des menschlichen Fussess. MedizinZeitung. 24169-2477.

2. Schulte (1897) Die sogenannte Fussgeschwulst. Arch Klin Chir. 55: 872 (in German). 
Citation: Castro SD, Joosse P, Unlu C, Steller EP (2014) Stress Fractures of the Tibia after Jogging. J Trauma Treat S2: 006. doi:

Page 4 of 4

3. Jones BH, Harris JM, Vinh TN, Rubin C (1989) Exercise-induced stress fractures and stress reactions of bone: epidemiology, etiology, and classification. Exerc Sport Sci Rev 17: 379-422.

4. Spiker AM, Dixit S, Cosgarea AJ (2012) Triathlon: running injuries. Sports Med Arthrosc 20: 206-213.

5. Cleek TM, Whalen RT (2005) Effect of activity and age on long bones using a new densitometric technique. Med Sci Sports Exerc 37: 1806-1813.

6. Giladi M, Milgrom C, Stein M, Kashtan H, Margulies J, et al. (1987) External rotation of the hip. A predictor of risk for stress fractures. Clin Orthop Relat Res : 131-134.

7. Bennell KL, Malcolm SA, Thomas SA, Ebeling PR, McCrory PR, et al. (1995) Risk factors for stress fractures in female track-and-field athletes: a retrospective analysis. Clin J Sport Med 5: 229-235.

8. Garrett WE Jr, Safran MR, Seaber AV, Glisson RR, Ribbeck BM (1987) Biomechanical comparison of stimulated and nonstimulated skeletal muscle pulled to failure. Am J Sports Med 15: 448-454.

9. Crossley K, Bennell KL, Wrigley T, Oakes BW (1999) Ground reaction forces, bone characteristics, and tibial stress fracture in male runners. Med Sci Sports Exerc 31: 1088-1093.

10. Bennell KL, Brukner PD (1997) Epidemiology and site specificity of stress fractures. Clin Sports Med 16: 179-196.

11. Kilcoyne KG, Dickens JF, Rue JP (2013) Tibial stress fractures in an active duty population: long-term outcomes. J Surg Orthop Adv 22: 50-53.

12. Kiuru MJ, Pihlajamäki HK, Ahovuo JA (2004) Bone stress injuries. Acta Radiol 45: 317-326.

13. Snyder RA, Koester MC, Dunn WR (2006) Epidemiology of stress fractures. Clin Sports Med 25: 37-52, viii.

14. Brunet ME, Cook SD, Brinker MR, Dickinson JA (1990) A survey of running injuries in 1505 competitive and recreational runners. J Sports Med Phys Fitness 30: 307-315.

15. Johnson AW, Weiss CB Jr, Wheeler DL (1994) Stress fractures of the femoral shaft in athletes--more common than expected. A new clinical test. Am J Sports Med 22: 248-256.

16. Brukner P, Bradshaw C, Khan KM, White S, Crossley K (1996) Stress fractures: a review of 180 cases. Clin J Sport Med 6: 85-89.

17. Matheson GO, Clement DB, McKenzie DC, Taunton JE, Lloyd-Smith DR, et al. (1987) Stress fractures in athletes. A study of 320 cases. Am J Sports Med 15: 46-58

18. Fredericson M, Bergman AG, Hoffman KL, Dillingham MS (1995) Tibial stress reaction in runners. Correlation of clinical symptoms and scintigraphy with a new magnetic resonance imaging grading system. Am J Sports Med 23: 472-481.

19. Mulligan ME (1995) The "gray cortex ": an early sign of stress fracture. Skeletal Radiol 24: 201-203.

20. Roub LW, Gumerman LW, Hanley EN Jr, Clark MW, Goodman M, et al. (1979) Bone stress: a radionuclide imaging perspective. Radiology 132: 431-438.

21. Hoch AZ, Pepper M, Akuthota V (2005) Stress fractures and knee injuries in runners. Phys Med Rehabil Clin N Am 16: 749-777.

22. Anderson MW1, Greenspan A (1996) Stress fractures. Radiology 199: $1-12$.

23. Martin SD, Healey JH, Horowitz S (1993) Stress fracture MRI Orthopedics 16: 75-78.

24. Stafford SA, Rosenthal DI, Gebhardt MC, Brady TJ, Scott JA (1986) MRI in stress fracture. AJR Am J Roentgenol 147: 553-556.

25. Bergman AG, Fredericson M, Ho C, Matheson GO (2004) Asymptomatic tibial stress reactions: MRI detection and clinical follow-up in distance runners. AJR Am J Roentgenol 183: 635-638.

26. Swenson EJ Jr1, DeHaven KE, Sebastianelli WJ, Hanks G, Kalenak A, et al. (1997) The effect of a pneumatic leg brace on return to play in athletes with tibial stress fractures. Am J Sports Med 25: 322-328.

27. Engber WD (1977) Stress fractures of the medial tibial plateau. J Bone Joint Surg Am 59: 767-769.

28. Harolds JA (1981) Fatigue fractures of the medial tibial plateau. South Med J 74: 578-581

29. Kaeding CC, Yu JR, Wright R, Amendola A, Spindler KP (2005) Management and return to play of stress fractures. Clin J Sport Med 15: 442-447.

30. Plasschaert VF, Johansson CG, Micheli LJ (1995) Anterior tibial stress fracture treated with intramedullary nailing: a case report. Clin J Sport Med 5: 58-61.

31. Swiontkowski MF, Engelberg R, Martin DP, Agel J (1999) Short musculoskeletal function assessment questionnaire: validity, reliability, and responsiveness. J Bone Joint Surg Am 81: 1245-1260.

32. Gallo RA, Plakke M, Silvis ML (2012) Common Leg Injuries of LongDistance Runners: Anatomical and Biomechanical Approach. Sports Health 4: 485-495.

33. Swischuk LE, Jadhav SP (2014) Tibial stress phenomena and fractures: imaging evaluation. Emerg Radiol 21: 173-177.

34. Caesar BC, McCollum GA, Elliot R, Williams A, Calder JD (2013) Stress fractures of the tibia and medial malleolus. Foot Ankle Clin 18: 339-355. 